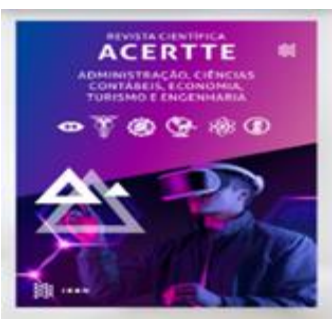

REVISTA CIENTÍFICA ACERTTE

\title{
FERRAMENTAS DA ADMINISTRAÇÃO: COMO SÃO APLICADAS NA GESTÃO EMPRESARIAL NA FIDELIZAÇÃO DE CLIENTES?
}

\author{
ADMINISTRATION TOOLS: HOW ARE THEY APPLIED IN BUSINESS MANAGEMENT IN \\ CUSTOMER LOYALTY?
}

\section{HERRAMIENTAS DE ADMINISTRACIÓN: ¿CÓMO SE APLICAN EN LA GESTIÓN EMPRESARIAL PARA LA FIDELIZACIÓN DEL CLIENTE?}

\author{
Claudio Chiusoli ${ }^{1}$, Elizabeth Emperatriz Garcia-Salirrosas ${ }^{2}$, Thiago Ferreira Spiri ${ }^{3}$, Andressa Antonio ${ }^{4}$
}

Submetido em: $31 / 07 / 2021$

e1327

Aprovado em: 08/09/2021

https://doi.org/10.47820/acertte.v1i3.27

\section{RESUMO}

Considera-se que o uso das ferramentas de gestão empresarial traz benefícios para as organizações em busca de uma vantagem competitiva. O objetivo do estudo é analisar como se dá o uso das ferramentas da administração na praticas da gestão empresarial com o respectivo processo de satisfação e fidelização com o cliente. Como metodologia, considera-se um estudo exploratório e quantitativo. Como método de estudo, foi considerado amostragem não probabilística mediante 107 entrevistas aplicadas via plataforma Google Forms. Os principais achados apontam que 32,3\% utilizam a propaganda e promoções como estratégias para atrair novos clientes; $58,7 \%$ apontam as redes sociais como forma de contato com o cliente e $65,4 \%$ costumam avaliar a satisfação dos clientes, e com isso, apenas $29,6 \%$ tem alguma forma de cartão fidelidade como estratégia de fidelização do cliente. Quanto as ferramentas para gestão estratégica, apesar de baixos índices de utilização, tem-se que $26,9 \%$ faz análise SWOT, 26,0\% faz plano de negócios, 23,1\% usa o ciclo PDCA, 22,1\% utilizam o $5 \mathrm{~W} 2 \mathrm{H}$ e $21,2 \%$ o CRM como estratégia da empresa. O estudo contribuiu ao verificar como as empresas procuraram satisfazer e fidelizar seus clientes, se utilizam alguma ferramenta de gestão para isso e quais estratégias são utilizadas em busca de um relacionamento duradouro, e como avaliam o nível de satisfação dos clientes com os produtos e/ou serviços ofertados. A maioria dos gestores entrevistados não utilizam sistemas de gestão para atrair e manter seus clientes, isso pode ser explicado por desconhecimento ou por considerarem inviável esse investimento, o que aponta uma lacuna entre o uso das ferramentas de gestão e seus conceitos.

PALAVRAS-CHAVE: CRM. Ferramentas de gestão. Fidelização de clientes

\begin{abstract}
It is considered that the use of business management tools brings benefits to organizations in search of a competitive advantage. The objective is to analyze how administration tools are used in business management practices with the respective customer satisfaction and loyalty process. How methodology, it is considered an exploratory and quantitative study. As a study method, non-probabilistic sampling was considered through 107 interviews applied by Google Forms platform. The main findings show that $32.3 \%$ use advertising and promotions as strategies to attract new customers; $58.7 \%$ point to social networks as a way of contacting the customer and 65.4\% usually assess customer satisfaction, and with that, only $29.6 \%$ have some form of loyalty card as a customer loyalty strategy. As for the tools for strategic management, despite low usage rates, $26.9 \%$ do SWOT analysis, $26.0 \%$ do business plan, $23.1 \%$ use the PDCA cycle, 22.1\% use the 5W2H and $21.2 \%$ the CRM as the company's strategy. The study contributed by analyzing how companies do to satisfy and retain their customers, whether they use any management tool for this and what strategies are used in search of a lasting relationship, as

\footnotetext{
1 Universidade Estadual do Centro-Oeste - UNICENTRO

2 Docente da Universidad Nacional Tecnológica de Lima Sur - UNTELS- Escuela Profesional de Administración de Empresas - Lima - Perú

${ }^{3}$ Mestrado em Administração (UEL) e docente do ensino superior na área de Administração

4 Discente do curso de administração da Universidade Estadual do Centro Oeste - UNICENTRO/Pr
} ACERTTE - Administração, Ciências Contábeis, Economia, Turismo, Tecnologia e Engenharia
\end{abstract}




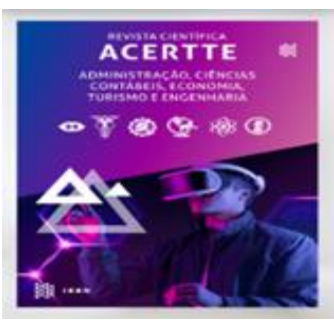

\section{REVISTA CIENTÍFICA ACERTTE ISSN 2763-8928}

well as evaluating the level of customer satisfaction with the products and/or services offered. And the most of the interviewed managers do not use management systems to attract and keep their customers, probably due to lack of knowledge or they consider this investment unfeasible, which points to a gap between the use of management tools and their concepts.

KEYWORDS: CRM. Management tools. Customer loyalty

\section{RESUMEN}

Se considera que el uso de herramientas de gestión empresarial trae beneficios a las organizaciones que buscan una ventaja competitiva. El objetivo del estudio es analizar el uso de las herramientas de administración en las prácticas de la gestión empresarial para la satisfacción y fidelización del cliente. Como metodología, se considera un estudio exploratorio y cuantitativo. Como método se consideró el muestreo no probabilístico a través de 107 entrevistas aplicadas a través de la plataforma Google Forms. Los principales hallazgos indican que el 32,3\% utiliza la publicidad y las promociones como estrategias para atraer nuevos clientes; El 58,7\% apunta a las redes sociales como una forma de contactar con el cliente y el 65,4\% suele valorar la satisfacción del cliente; solo el 29,6\% aplica algún tipo de tarjeta de fidelización como estrategia de fidelización del cliente. En cuanto a las herramientas para la gestión estratégica, a pesar de las bajas tasas de uso, el 26,9\% hace análisis DAFO, el 26,0\% hace plan de negocio, el 23,1\% utiliza el ciclo PDCA, el 22,1\% utiliza el 5W2H y el 21,2\% CRM como estrategia de la empresa. El estudio contribuye con el análisis referente a las acciones que realizan las empresas para satisfacer y fidelizar a sus clientes, el uso que hacen de alguna herramienta de gestión para ello y las estrategias que utilizan en busca de una relación duradera; así como evaluar el nivel de satisfacción del cliente con los productos y / o servicios ofrecidos. La mayoría de los gerentes entrevistados no utilizan sistemas de gestión para atraer y retener a sus clientes, probablemente por su desconocimiento o por considerar inviable esta inversión, lo que apunta a una brecha entre el uso de herramientas de gestión y sus conceptos.

PALABRAS CLAVES: CRM. Herramientas de gestión. Fidelización de clientes

\section{INTRODUÇÃO}

O marketing, em seu conceito primário, tem como objetivo salientar que pode ser tratado como uma área ou como ações estratégicas, porém sua base é a palavra em inglês que significa que o mercado "Market" está em movimento com o sufixo "ing". Ou seja, os clientes estão buscando novos produtos e ou serviços, considerando o aumento da concorrência e novas formas de comunicação por meio da velocidade tecnológica, sendo assim, pensar em um relacionamento com o cliente oportunizará um diferencial competitivo no mercado que atua (SILVA; MINCIOTTI e GIL, 2013).

Conforme Medeiros (2016) a gestão do relacionamento com o cliente, conhecido como CRM (Customer Relationship Management) está diretamente ligada ao compartilhamento e reutilização de conhecimento, além do gerenciamento de processos e qualidade de comunicação e relacionamento, visando um aumento na produtividade das pessoas e, consequentemente, da organização.

A proposta do CRM é coletar informações sobre os clientes. Essa ferramenta auxilia as decisões de marketing de relacionamento de uma empresa junto aos seus clientes. $O$ database de marketing possibilita o conhecimento sobre os clientes, prevendo comportamentos. $\mathrm{O}$ uso adequado desses dados depende de uma política de relacionamento da empresa com os consumidores, aumentando as oportunidades de oferecer aos clientes o produto certo (SWIFT, 2014). 


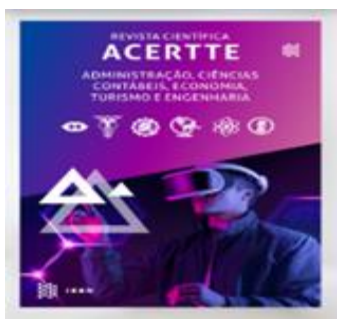

\section{REVISTA CIENTÍFICA ACERTTE ISSN 2763-8928}

Madruga (2004) afirma que o CRM é a ajuda da tecnologia para o Marketing de relacionamento. O autor também fala que os dois devem andar juntos, um completando o outro e vice-versa. Além disso, o mesmo autor afirma que o CRM deixou de ser um sistema de relacionamento e já é encarado como uma estratégia, visão, orientação para o cliente entre outras atribuições.

Portanto, este trabalho procura mostrar que o marketing de relacionamento com cliente pode ser um importante instrumento de diferenciação e vantagem competitiva para as empresas. Assim, Kotler (2003) afirma que o marketing de relacionamento representa uma importante mudança de paradigma, por se tratar de evolução da mentalidade competitiva e conflituosa para uma nova abordagem pautada pela interdependência e cooperação.

A justificativa da pesquisa se dá devido ao exposto por Oliveira (2015) onde ele afirma que 0 conceito de CRM parte da premissa que é de cinco até dez vezes mais caro obter um novo cliente do que reter os existentes, e que, o importante não é ter uma imensa carteira de clientes, mas ter uma boa base de clientes rentáveis.

Além disso, Sales (2014) aponta que a fidelização também está intimamente relacionada ao marketing de relacionamento, sendo que esses dois fatores se complementam.

A busca por um diferencial em meio a tantos concorrentes é imprescindível, ou seja, oferecer um produto e serviço de qualidade é de suma importância. Os clientes estão gradativamente mais exigentes quanto ao atendimento, e é nesse contexto que Ferreira, Filipchiuk e Silva (2014) afirmam que para continuar no mercado, a empresa precisa, além de oferecer qualidade no produto, dedicar-se inteiramente à qualidade dos serviços ao cliente.

Desse modo, cabe a seguinte problematização: como é o uso por parte da gestão empresarial a aplicação das ferramentas da administração a fim de melhorar o relacionamento com os clientes e por sua vez a fidelização?

Assim, o trabalho tem como objetivo de analisar como se dá o uso das ferramentas da administração nas práticas da gestão empresarial com o respectivo processo de satisfação e fidelização com o cliente.

O estudo se justifica, pois os gestores não têm informações seguras e/ou informatizadas sobre o impacto que um mau relacionamento com o cliente pode gerar uma insatisfação, assim, as críticas são feitas normalmente para os mesmos durante o atendimento e as vezes não estrutura adequada, nem tempo para atender a tudo o que os clientes falam, reivindicam ou sugerem.

Essa situação é muito comum nas organizações, na maioria das vezes o que se diz para os vendedores não chega aos ouvidos dos donos ou gerentes, fazendo com que as reivindicações não sejam atendidas e, dessa forma, prejudica a imagem desses estabelecimentos perante os clientes. Por isso, é de extrema importância que se ouça o que os clientes têm a dizer, visto que o objetivo principal de toda empresa é satisfazê-los.

Como objetivo específico, pretende-se identificar: i) se utilizam propaganda e promoções como estratégias para atrair novos clientes; ii) se utilizam as redes sociais como forma de contato com o cliente; iii) se utilizam alguma ferramenta para avaliar a satisfação dos clientes; iv) se utilizam o cartão 


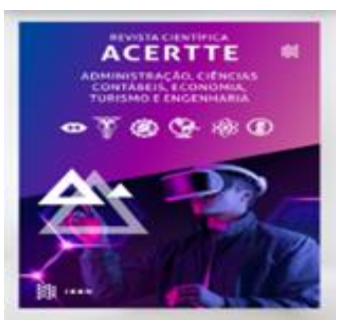

\section{REVISTA CIENTÍFICA ACERTTE ISSN 2763-8928}

fidelidade como estratégia de fidelização do cliente e v) se utilizam o ciclo PDCA, plano de negócios, análise SWOT, 5W2H e CRM como parte da estratégia da empresa.

O presente artigo foi estruturado inicialmente pela introdução, seguindo com a apresentação dos conceitos teóricos; na sequência apresenta os procedimentos metodológicos adotados para realizar a pesquisa. A seção seguinte refere-se às análises dos dados coletados e discriminação dos resultados obtidos, e, por fim, apresenta as considerações finais do estudo.

\section{REFERENCIAL TEÓRICO}

No tópico do referencial teórico são abordados os principais conceitos e definições das ferramentas da administração, bem como os fatores que contribuem para o processo satisfação e fidelização de clientes, o marketing de relacionamento.

\section{Ferramentas da administração}

Os princípios do CRM consideram a junção da filosofia do marketing de relacionamento, cujo objetivo é voltado à importância de estabelecer um relacionamento estável e duradouro com os clientes, aliado a tecnologia da informação, que provê ferramentas de informatização e telecomunicações integrados de forma única. Essa integração pressupõe que a empresa esteja disposta a manter um relacionamento com o apoio de processos operacionais mais rápidos e que selecione a tecnologia adequada a cada tipo de organização (MEDEIROS, 2016).

O CRM se propõe a coletar informações sobre os clientes. Essa ferramenta auxilia as decisões estratégicas de marketing de relacionamento de uma empresa junto aos seus clientes. $O$ database de marketing possibilita o conhecimento sobre os clientes, prevendo comportamentos. $\mathrm{O}$ uso adequado desses dados depende de uma política de relacionamento da empresa com os consumidores aumentando as oportunidades de oferecer aos clientes o produto certo (SWIFT, 2014).

Para Everatt e Morrison (2015), implementar CRM num departamento específico, com uma visão de melhorias de curto prazo, não traz os benefícios esperados. A implementação de CRM deve abranger todo o processo de venda. Por essa razão, o CRM deve ser implementado em partes, iniciando das atividades de pré-venda para as atividades de pós-vendas, onde todos os pontos de contato com o cliente podem ser cobertos.

O CRM proporciona um processo de significativa transformação dos clientes eventuais em clientes leais, baseando-se na premissa de que custa cinco vezes mais barato manter os atuais clientes do que obter novos, uma vez para obter novos clientes é necessário investir tempo e recursos financeiros, seja em publicidade em outras estratégias. Entretanto, esses clientes já fidelizados precisam ser mais lucrativos possíveis para empresa (SWIFT, 2014).

Peppers e Rogers (2014) definem o CRM como o método mais sofisticado e eficiente para as empresas aumentarem a rentabilidade com uma visão ampla de negócio, voltada para o entendimento e antecipação das necessidades dos clientes atuais e potenciais. 


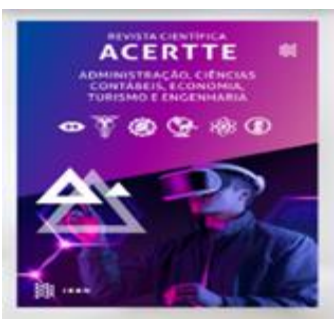

\section{REVISTA CIENTÍFICA ACERTTE} ISSN 2763-8928

Os autores afirmam, ainda, que o CRM implica em uma filosofia one-to-one de relacionamentos com os clientes, onde a empresa se direciona para o cliente individualmente, tornando-se capaz de tratar o mesmo de maneira diferente dos demais, aprendendo como ele deseja ser tratado.

De acordo com a perspectiva de Torres e Fonseca (2016), o marketing de relacionamento é de suma importância para as organizações, uma vez que toda empresa necessita dos consumidores para manter-se no mercado, e, não obstante, precisa que os mesmos estejam satisfeitos com os produtos e/ou serviços ofertados pela empresa.

Complementando os autores, Ferreira, Filipchiuk e Silva (2014) elencam que para um negócio obter sucesso as empresas devem investir em relacionamento duradouro com os clientes. Portanto, a principal estratégia é o que se conhece como marketing de relacionamento, que demonstra como ações de relacionamento podem influenciar no comportamento dos consumidores e, se bem sucedido, em um relacionamento seguro e duradouro.

$\mathrm{E}$, a atenção aos pequenos detalhes faz toda a diferença. Atualmente, um cliente exige um relacionamento cada vez mais forte e eficaz. As estratégias do CRM têm que ser inteligentes e criativas, a fim de identificar e selecionar as formas de relacionamento com os clientes que excedam às expectativas dos mesmos. Ter uma gestão preparada para esta demanda é algo que pode fazer a diferença (ZEITHAML; BITNER; 2017).

É uma filosofia de fazer negócios, uma orientação estratégica cujo foco está na manutenção e no aperfeiçoamento dos atuais clientes, e não na conquista de novos clientes. Esta filosofia pressupõe que os clientes preferem ter um relacionamento continuado a trocar regularmente de fornecedores, pois é mais barato manter um cliente do que atrair um novo (ZEITHAML; BITNER; 2017).

\section{Marketing de relacionamento}

A satisfação dos clientes tornou-se um diferencial de suma importância para as organizações. Atualmente as organizações procuram suprir as necessidades de seus clientes, para obtenção de sucesso e até mesmo garantir a sobrevivência no mercado. Para atender às expectativas dos clientes o serviço tem que ser de qualidade e acompanhado de um bom atendimento (ALMEIDA, 2017).

Para Oliveira (2016), aumentar a satisfação de um cliente leva a precisão de medi-la e para tanto é necessário saber a qualidade percebida por ele. Essa medida equivale ao intervalo entre o serviço esperado e a percepção do serviço realmente recebido.

Cabe ressaltar que a busca em fidelizar o cliente é um processo contínuo compromissado por toda organização através de atitudes que passam confiança, respeito e garantias de direito, assim fazendo com que faça parte da sua cultura e missão (ALMEIDA, 2017). As empresas para sobreviveram ao mercado precisam fidelizar seus clientes e isto significa que a empresa deve pesquisar as expectativas e o desejo dos seus clientes em relação aos produtos e serviços que fornecem a comunidade, para então se organizarem da melhor forma possível para atender a estas necessidades (TORRES, 2015). 


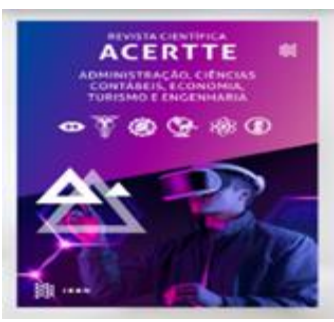

\section{REVISTA CIENTÍFICA ACERTTE ISSN 2763-8928}

Os clientes de maior poder aquisitivo são os alvos de assédios das empresas concorrentes, já esses clientes possuem maiores poderes de compras, consequentemente, podem elevar o lucro da empresa. Logo assim, é importante que as empresas possuam serviços eficientes de pós-venda, para reduzir perdas de clientes para os concorrentes (SILVA, 2014).

De acordo com Araújo (2016), os consumidores as vezes não têm uma noção precisa do valor do produto ou serviços e nem mesmo relacionam com objetividade os custos desses valores para a empresa. O valor para o cliente é a diferença entre os valores que o cliente ganha comprando e usando um produto e os custos para obter esse produto

De acordo com o Nepomucena (2014) as empresas devem buscar conhecer se o consumidor final está realmente satisfeito, através de pesquisas com uma amostra de sua clientela por um determinado período, entrando em contato com eles, para analisar os resultados da pesquisa, possibilitando uma visão dos seus pontos fracos e fortes. Uma das ferramentas para o uso do pósvenda é através do telemarketing que proporciona mais informações relativas dos seus produtos ou serviços. Araújo (2016) afirma que por meio do telemarketing a empresa conhecerá e manterá contato com seus clientes, poderá informar benefícios adicionais aos seus clientes efetivos e ainda permanecerá no mercado competitivamente.

A qualidade no atendimento se apresenta também como resultado do bom trabalho dos funcionários da empresa, uma vez que estes se comprometem com a proposta da empresa e visa fidelizar o cliente através de ação que vão ao encontro com as necessidades dos mesmos (DIAS, 2015).

A qualidade aplicada aos serviços e produtos é uma estratégia adotada pelas empresas para satisfazer e, mais ainda, prevê as necessidades futuras tanto dos clientes efetivos quanto dos clientes em potencial. Trata-se de uma prática organizacional extremamente ampla, a qual vem processando as informações obtidas e distribuindo os resultados de modo que haja uma equilibrada interação. Todas as atenções estão voltadas para o cliente (OLIVEIRA, 2016).

\section{METODOLOGIA}

Foi realizado uma pesquisa bibliográfica em livros e artigos para dar embasamento ao artigo, a qual, de acordo com Gil (2017), é elaborada com base em tema publicados sobre determinado tema de pesquisa. Deste modo, diversas fontes de natureza bibliográfica foram utilizadas, tais como: livros clássicos e artigos científicos, objetivando do tema objeto do estudo.

Quanto à natureza das variáveis foi um estudo quantitativo, de cunho exploratório, onde foram aplicados questionários fechados por meio da plataforma Google Forms para gestores localizados em uma cidade do interior do Paraná, utilizando-se de escala nominal e intervalar.

Polit, Becker e Hungler (2014) destacam que a pesquisa quantitativa tem pensamento positivista lógico e por isso tende a enfatizar o raciocínio dedutivo, as regras da lógica e os atributos mensuráveis da experiência humana.

A pesquisa buscou descrever os resultados obtidos a partir das questões realizadas com gestores de empresas para uma melhor compreensão de quão importante é a utilização das 


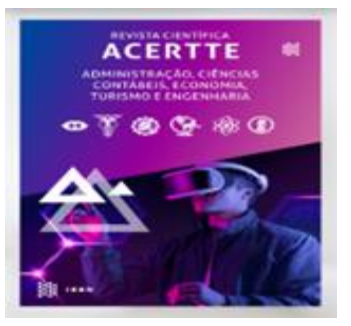

\section{REVISTA CIENTÍFICA ACERTTE ISSN 2763-8928}

ferramentas de CRM em busca da fidelização de clientes. Para Triviños (2015) a pesquisa exploratória exige informações do investigador e pretende descrever fatos e fenômenos sobre determinado tema, a partir de uma questão problema.

A procedência dos dados foi primária, tendo levantamento por meio eletrônico, sendo aplicados 107 questionários, contendo doze variáveis de autopreenchimento pelos gestores das empresas investigadas, nesse caso, considerando os 3 perfis, por gênero, faixa etária e tempo da empresa no mercado, no período de agosto de 2020.

Além disso, o recorte foi transversal, uma única vez, por meio da survey que, segundo Fonseca (2017) trata-se da pesquisa que diz respeito à obtenção e levantamento de dados e informações sobre as opiniões de determinado grupo. No que diz respeito à amostragem, foi não-probabilística por conveniência, que segundo com Schiffman (2015), ocorre quando o pesquisador seleciona membros da população mais acessíveis não havendo sorteio entre os participantes.

Em relação à técnica de análise estatística, consistiu-se em análises univariadas e bivariadas baseadas em frequências relativas e processados por meio do software IBM SPSS Statistics 20 (Statistical Package for the Social Sciences).

A técnica estatística utilizada foi o teste Qui-Quadrado, que tem como proposta avaliar se as observações não pareadas entre duas variáveis independentes entre si, aplicadas ao nível de significância de 5\%, para descrever se deve ou não rejeitar as hipóteses elaboradas. No caso, se o pvalor obtido for menor ou igual a $5 \%(p \leq 0,05)$, as variáveis são independentes, e as hipóteses devem ser rejeitadas; por outro lado, se for acima de 5\%, não devem ser rejeitadas, isto é, as variáveis são dependentes (SIEGEL; CASTELLAN, 2017).

Nesse sentido, o teste qui-quadrado foi utilizado para verificar a relação das variáveis estudadas considerando o perfil dos respondentes por gênero, faixa etária e tempo da empresa no mercado.

Obtidas essas informações, as hipóteses da pesquisa foram:

H0: A opinião dos gestores em relação às variáveis investigadas segmentadas por gênero é semelhante, portanto, não há diferença significativa (masculino e feminino).

H1: A opinião dos gestores em relação às variáveis investigadas segmentadas por faixa etária é semelhante, portanto, não há diferença significativa (20 a 30 anos, 31 a 40 anos e acima de 40 anos). H2: A opinião dos gestores em relação às variáveis investigadas segmentadas por tempo de existência da empresa no mercado é semelhante, portanto, não há diferença significativa (até 3 anos, de 4 a 6 anos e acima de 6 nos).

\section{RESULTADO E DISCUSSÃO}

Nessa parte do estudo, em relação a análise dos resultados, são compostas por 12 Tabelas segmentados por gênero, faixa etária e tempo da empresa no mercado. Nas Tabelas 1 a 3 tem-se primeiramente os dados pessoais e da empresa; e após, das Tabela 4 ao 12, os resultados obtidos 


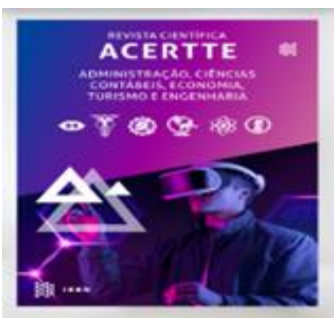

\section{REVISTA CIENTÍFICA ACERTTE ISSN 2763-8928}

conforme objetivos propostos; por fim, o Tabela 13 apresenta o resumo dos resultados do teste QuiQuadrado, apontando se deve rejeitar ou não as hipóteses H0, H1 e H2 investigadas.

A Tabela 1 refere-se à variável "Perfil do gestor quanto ao gênero"; mostra um p-valor de 0,039 para a hipótese $\mathrm{H} 1$ e um p-valor de 0,515 para a hipótese $\mathrm{H} 2$, sugerindo que a hipótese $\mathrm{H} 1$ deve ser rejeitada e a hipótese $\mathrm{H} 2$ não deve ser rejeitada.

Ao analisar o resultado geral o perfil dos entrevistados quanto ao gênero, é possível notar que há um equilíbrio entre homens (57,7\%) e mulheres (42,3\%) com uma pequena porcentagem majoritariamente masculina. Ao comparar os dados da faixa etária, verifica-se dos entrevistados com idade superior a 40 anos, predomina o gênero masculino com $66,7 \%$ e na faixa etária de 20 a 30 anos a maioria composto pelas mulheres com $62,1 \%$, o que é explicado pelo teste do Qui Quadrado que associa que a maior parte das mulheres gestoras são mais jovens, enquanto a maioria dos homens a frente das empresas estão numa faixa etária mais elevada.

No que diz respeito ao tempo das empresas no mercado de trabalho, a maior parte comandada por indivíduos do sexo masculino em proporção está na faixa de empresa com mais de 6 anos de mercado, como $63,4 \%$.

Tabela 1 - Perfil do gestor: Sexo

\begin{tabular}{cccccccc}
\hline & \multicolumn{3}{c}{ Faixa etária } & \multicolumn{5}{c}{ Tempo empresa mercado } \\
\hline & $\mathbf{2 0} / \mathbf{3 0}$ & $\mathbf{3 1 / 4 0}$ & $\mathbf{4 0 +}$ & Até 3 & De $\mathbf{4} / \mathbf{6}$ & $\mathbf{6 +}$ & Total \\
\hline Masculino & $37,9 \%$ & $63,9 \%$ & $66,7 \%$ & $50,0 \%$ & $58,1 \%$ & $63,4 \%$ & $57,7 \%$ \\
\hline Feminino & $62,1 \%$ & $36,1 \%$ & $33,3 \%$ & $50,0 \%$ & $41,9 \%$ & $36,6 \%$ & $42,3 \%$ \\
\hline Total Geral & $100,0 \%$ & $100,0 \%$ & $100,0 \%$ & $100,0 \%$ & $100,0 \%$ & $100,0 \%$ & $100,0 \%$ \\
\hline \multicolumn{7}{c}{ Fonte: Dados da pesquisa (2020) }
\end{tabular}

A Tabela 2 refere-se à "Perfil do gestor quanto a faixa etária"; mostra um p-valor de 0,039 para a hipótese $\mathrm{H} 0$ e um p-valor de 0,083 para a hipótese $\mathrm{H} 2$. Assim, a hipótese $\mathrm{H} 0$ deve ser rejeitado, enquanto a hipótese $\mathrm{H} 2$ não deve ser rejeitada.

No que diz respeito à faixa etária dos entrevistados, percebe-se que há também um equilíbrio entre as porcentagens de cada faixa, sendo que há maior quantidade de entrevistados entre os indivíduos com mais de 40 anos (37,5\%). Isso deve-se ao fato de que, para se tornar um gestor, geralmente é preciso tempo e experiência. Outro dado relevante é que a maioria dos gestores do sexo masculino estão na faixa etária com mais de 40 anos, enquanto a maioria do sexo feminino estão na faixa dos 20 aos 30 anos.

Tabela 2 - Perfil do gestor: faixa etária

$$
\text { Gênero }
$$
Tempo empresa mercado

\begin{tabular}{ccccccc}
\hline Faixa etária & Feminino & Masculino & Até 3 & De 4 / $\mathbf{6}$ & $\mathbf{6 +}$ & Total \\
\hline $20 / 30$ & $40,9 \%$ & $18,3 \%$ & $43,8 \%$ & $16,1 \%$ & $24,4 \%$ & $27,9 \%$ \\
\hline $31 / 40$ & $29,5 \%$ & $38,3 \%$ & $31,3 \%$ & $45,2 \%$ & $29,3 \%$ & $34,6 \%$ \\
\hline $40+$ & $29,5 \%$ & $43,3 \%$ & $25,0 \%$ & $38,7 \%$ & $46,3 \%$ & $37,5 \%$ \\
\hline Total Geral & $100,0 \%$ & $100,0 \%$ & $100,0 \%$ & $100,0 \%$ & $100,0 \%$ & $100,0 \%$ \\
\hline \multicolumn{7}{c}{ Fonte: Dados da pesquisa (2020) }
\end{tabular}




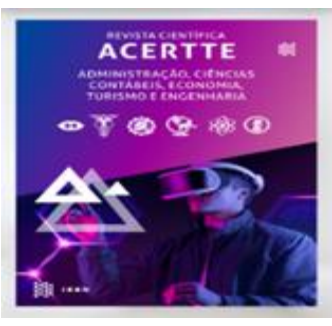

\section{REVISTA CIENTÍFICA ACERTTE ISSN 2763-8928}

A Tabela 3 apresenta os dados referente ao "Perfil da empresa quanto ao tempo no mercado"; mostra um p-valor de 0,515 para a hipótese $\mathrm{H} 0$ e um p-valor de 0,083 para a hipótese $\mathrm{H} 1$. O teste estatístico aplicado sugere que ambas as hipóteses, $\mathrm{HO}$ e H1, não devem ser rejeitadas, ou seja, ao segmentar os dados por gênero e faixa etária não apresenta diferença significativa entre as respostas dos gestores.

Ao analisar os resultados quanto ao tempo da empresa no mercado em que atua, verifica-se com 39,4\% o grupo de empresas que está acima de seis anos no mercado. Em relação ao gênero dos entrevistados, entre os homens aparece com 43,3\% na gestão de empresa acima de 6 anos no mercado, quando compara com proporção das mulheres, que é de $34,1 \%$.

Tabela 3 - Tempo da empresa no mercado

\begin{tabular}{ccccccc}
\hline \multicolumn{2}{c}{ Gênero } & \multicolumn{3}{c}{ Faixa etária } \\
\hline Tempo empresa & Feminino & Masculino & $\mathbf{2 0 ~ / ~ 3 0 ~}$ & $\mathbf{3 1 / 4 0}$ & $\mathbf{4 0 +}$ & Total \\
\hline Até 3 & $36,4 \%$ & $26,7 \%$ & $48,3 \%$ & $27,8 \%$ & $20,5 \%$ & $30,8 \%$ \\
\hline De 4 / 6 & $29,5 \%$ & $30,0 \%$ & $17,2 \%$ & $38,9 \%$ & $30,8 \%$ & $29,8 \%$ \\
\hline $6+$ & $34,1 \%$ & $43,3 \%$ & $34,5 \%$ & $33,3 \%$ & $48,7 \%$ & $39,4 \%$ \\
\hline Total Geral & $100,0 \%$ & $100,0 \%$ & $100,0 \%$ & $100,0 \%$ & $100,0 \%$ & $100,0 \%$ \\
\hline \multicolumn{7}{c}{ Fonte: Dados da pesquisa $(2020)$}
\end{tabular}

A Tabela 4 refere-se à variável "Estratégias para atrair novos clientes"; mostra um p-valor de 0,296 para a hipótese $\mathrm{H} 0$, um $\mathrm{p}$-valor de 0,141 para a hipótese $\mathrm{H} 1$ e um $\mathrm{p}$-valor de 0,226 para a hipótese $\mathrm{H} 2$, sugerindo que as hipóteses $\mathrm{H} 0, \mathrm{H} 1$ e H2 não devem ser rejeitadas, ou seja, nos cruzamentos dos dados por gênero, faixa etária e tempo da empresa no mercado, apresenta que não há diferença significativa entre as respostas dos gestores.

Em relação as estratégias aplicadas para captar novos cliente, é possível perceber que parte das empresas pesquisadas (32,3\%) investem em propaganda e promoções como os principais recurso para conquistar novos mercados, seguido de um bom atendimento $(24,2 \%)$ e preço $(20,2 \%)$. Em contrapartida a estratégias menos utilizadas é o reforço na comunicação a respeito da qualidade dos produtos $(5,1 \%)$, mesmo, considerando que este ainda é um aspecto relevante.

Os dados sugerem que tais práticas, de acordo com a abordagem de Ráiz, Matarello e Lima (2015) para que a retenção de novos clientes seja bem sucedida, é necessário coletar, verificar e rastrear as informações sobre cada tipo de cliente. E o marketing de relacionamento engloba todos os níveis do planejamento estratégico e um maior conhecimento sobre os clientes significa que é possível entrar em novos mercados, que, para isso, a empresa pode utilizar banco de dados para identificar novas oportunidades de mercados. 


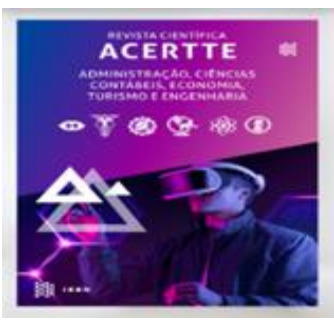

REVISTA CIENTÍFICA ACERTTE ISSN 2763-8928

\footnotetext{
FERRAMENTAS DA ADMINISTRAÇÃO: COMO SÃO APLICADAS NA GESTÃO EMPRESARIAL NA FIDELIZAÇÃO DE CLIENTES?
Claudio Chiusoli, Elizabeth Emperatriz Garcia-Salirrosas, Thiago Ferreira Spiri, Andressa Antonio
}

Tabela 4 - Estratégias para atrair novos clientes

\begin{tabular}{cccccccccc}
\hline & \multicolumn{2}{c}{ Gênero } & \multicolumn{3}{c}{ Faixa etária } & \multicolumn{5}{c}{ Tempo empresa mercado } \\
\hline & Feminino & Masculino & $\mathbf{2 0 ~ / 3 0}$ & $\mathbf{3 1 / 4 0}$ & $\mathbf{4 0 +}$ & Até 3 & De 4 / 6 & $\mathbf{6 +}$ & Total \\
\hline Promoções & $35,7 \%$ & $29,8 \%$ & $33,3 \%$ & $34,3 \%$ & $29,7 \%$ & $35,7 \%$ & $29,0 \%$ & $32,5 \%$ & $32,3 \%$ \\
\hline Atendimento & $19,0 \%$ & $28,1 \%$ & $18,5 \%$ & $11,4 \%$ & $40,5 \%$ & $21,4 \%$ & $9,7 \%$ & $37,5 \%$ & $24,2 \%$ \\
\hline Preços & $14,3 \%$ & $24,6 \%$ & $18,5 \%$ & $31,4 \%$ & $10,8 \%$ & $17,9 \%$ & $29,0 \%$ & $15,0 \%$ & $20,2 \%$ \\
\hline Redes sociais & $26,2 \%$ & $12,3 \%$ & $25,9 \%$ & $17,1 \%$ & $13,5 \%$ & $21,4 \%$ & $25,8 \%$ & $10,0 \%$ & $18,2 \%$ \\
\hline Qualidade produtos & $4,8 \%$ & $5,3 \%$ & $3,7 \%$ & $5,7 \%$ & $5,4 \%$ & $3,6 \%$ & $6,5 \%$ & $5,0 \%$ & $5,1 \%$ \\
\hline Total Geral & $100,0 \%$ & $100,0 \%$ & $100,0 \%$ & $100,0 \%$ & $100,0 \%$ & $100,0 \%$ & $100,0 \%$ & $100,0 \%$ & $100,0 \%$ \\
\hline \multicolumn{7}{c}{ Fonte: Dados da pesquisa $(2020)$}
\end{tabular}

A Tabela 5 refere-se à variável "Estratégias de fidelização de clientes"; mostra um p-valor de 0,752 para a hipótese $\mathrm{H} 0$, um p-valor de 0,382 para a hipótese $\mathrm{H} 1$, e um p-valor de 0,270 para a hipótese $\mathrm{H} 2$, sugerindo que as hipóteses $\mathrm{H} 0, \mathrm{H} 1$ e $\mathrm{H} 2$ não devem ser rejeitadas, ou seja, nos cruzamentos dos dados por gênero, faixa etária e tempo da empresa no mercado, não apresenta diferença significativa entre as respostas dos gestores.

Diante dos achados nessa questão, verifica-se os três métodos mais utilizados nas empresas entrevistadas que são o cartão fidelidade $(29,6 \%)$, descontos $(22,4 \%)$ e formas de pagamento $(21,4 \%)$ como meios para garantir que os consumidores habituais se tornem fiéis e firmem um relacionamento duradouro entre ambos, juntos somam $73,4 \%$.

Considerando, o tempo das empresas no mercado nota-se que a organização com mais de seis anos, utilizam o prazo de pagamento, com $27,5 \%$, como a principal estratégia de fidelização, e as empresas com menos tempo de existência, até 3 anos, utilizam os descontos, com 28,6\%. Já empresa de 4 a 6 anos de mercado o uso do cartão fidelidade é o mais citado, com $46,7 \%$. E a ação por meio de brindes é a forma menos adotada, com 9,2\%, como estratégia de fidelização.

É nessa perspectiva que Sousa (2016) aborda que a busca incessante pela fidelização de clientes tem gerado uma grande intensificação na competitividade entre as corporações, uma vez que estão focadas na avaliação quanto aos níveis de satisfação dos clientes e, com isso, a busca pelo sucesso deve estar voltada para o valor agregado ao cliente, gerando, assim, satisfação e fidelização.

Tabela 5 - Estratégias de fidelização de clientes

\begin{tabular}{cccccccccc}
\hline & \multicolumn{2}{c}{ Gênero } & \multicolumn{3}{c}{ Faixa etária } & \multicolumn{4}{c}{ Tempo empresa mercado } \\
\hline & Feminino & Masculino & $\mathbf{2 0} / \mathbf{3 0}$ & $\mathbf{3 1 / 4 0}$ & $\mathbf{4 0 +}$ & Até 3 & De 4/6 & $\mathbf{6 +}$ & Total \\
\hline Cartão fidelidade & $29,3 \%$ & $29,8 \%$ & $22,2 \%$ & $30,6 \%$ & $34,3 \%$ & $25,0 \%$ & $46,7 \%$ & $20,0 \%$ & $29,6 \%$ \\
\hline Descontos & $22,0 \%$ & $22,8 \%$ & $33,3 \%$ & $13,9 \%$ & $22,9 \%$ & $28,6 \%$ & $20,0 \%$ & $20,0 \%$ & $22,4 \%$ \\
\hline Prazo & $24,4 \%$ & $19,3 \%$ & $18,5 \%$ & $19,4 \%$ & $25,7 \%$ & $14,3 \%$ & $20,0 \%$ & $27,5 \%$ & $21,4 \%$ \\
\hline Crédito & $19,5 \%$ & $15,8 \%$ & $22,2 \%$ & $19,4 \%$ & $11,4 \%$ & $17,9 \%$ & $10,0 \%$ & $22,5 \%$ & $17,3 \%$ \\
\hline Brindes & $4,9 \%$ & $12,3 \%$ & $3,7 \%$ & $16,7 \%$ & $5,7 \%$ & $14,3 \%$ & $3,3 \%$ & $10,0 \%$ & $9,2 \%$ \\
\hline Total Geral & $100,0 \%$ & $100,0 \%$ & $100,0 \%$ & $100,0 \%$ & $100,0 \%$ & $100,0 \%$ & $100,0 \%$ & $100,0 \%$ & $100,0 \%$ \\
\hline \multicolumn{7}{c}{ Fonte: Dados da pesquisa $(2020)$} & & &
\end{tabular}

A Tabela 6 refere-se à variável "Utilização do ciclo PDCA na empresa"; mostra um p-valor de 0,690 para a hipótese $\mathrm{H} 0$, um p-valor de 0,353 para a hipótese $\mathrm{H} 1$, e um p-valor de 0,389 para a 


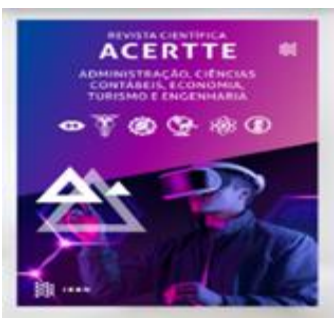

\section{REVISTA CIENTÍFICA ACERTTE ISSN 2763-8928}

hipótese $\mathrm{H} 2$, sugerindo que as hipóteses $\mathrm{H} 0, \mathrm{H} 1$ e $\mathrm{H} 2$ não devem ser rejeitadas, isto, nas segmentações dos dados por gênero, faixa etária e tempo de existência da empresa, não há diferença significativa na proporção de respostas entre os gestores.

Com o intuito de analisar o uso da ferramenta de gestão conhecida como Ciclo PDCA, foi possível perceber que a maioria dos gestores entrevistados $(76,9 \%)$ não utiliza essa ferramenta para fazer a gestão da rotina nas organizações. Entretanto, pode-se perceber que as organizações que estão a mais tempo no mercado $(29,3 \%)$ são as que mais utilizam essa ferramenta se comparado com as empresas com menos tempo (15,6\%), porém, ainda se observa um baixo percentual de uso.

Isso provavelmente se deve ao fato das empresas entrevistadas se enquadrarem como pequeno porte e sobretudo de gestão familiar, portanto, não consideram viável o uso dessa ou desconhecem tais ferramentas.

Pois com o uso do PDCA, de acordo com Alves (2015) como ferramenta, ajuda, na identificação e na análise das causas de um problema, além da busca por ações corretivas. Portanto, é importante seguir a sequência correta das etapas previstas na metodologia, além de utilizar as ferramentas adequadas em cada uma delas para que se possa obter a melhora significativa dos problemas e consequente atingimento das metas. Entretanto, é importante elencar que a utilização de metodologias exige comprometimento dos envolvidos para que todas as etapas, ações e melhorias identificadas sejam cumpridas e incorporadas à rotina.

Tabela 6 - Utilização do ciclo PDCA na empresa

\begin{tabular}{cccccccccc}
\hline & \multicolumn{2}{c}{ Gênero } & \multicolumn{3}{c}{ Faixa etária } & \multicolumn{4}{c}{ Tempo empresa mercado } \\
\hline & Feminino & Masculino & $\mathbf{2 0 / 3 0}$ & $\mathbf{3 1 / 4 0}$ & $\mathbf{4 0}+$ & Até 3 & De 4 / 6 & $\mathbf{6}+$ & Total \\
\hline Utiliza & $25,0 \%$ & $21,7 \%$ & $27,6 \%$ & $27,8 \%$ & $15,4 \%$ & $15,6 \%$ & $22,6 \%$ & $29,3 \%$ & $23,1 \%$ \\
\hline Não utiliza & $75,0 \%$ & $78,3 \%$ & $72,4 \%$ & $72,2 \%$ & $84,6 \%$ & $84,4 \%$ & $77,4 \%$ & $70,7 \%$ & $76,9 \%$ \\
\hline Total Geral & $100,0 \%$ & $100,0 \%$ & $100,0 \%$ & $100,0 \%$ & $100,0 \%$ & $100,0 \%$ & $100,0 \%$ & $100,0 \%$ & $100,0 \%$ \\
\hline \multicolumn{4}{c}{ Fonte: Dados da pesquisa $(2020)$}
\end{tabular}

A Tabela 7 demonstra informação referente à variável "Utilização do plano de negócios na empresa"; mostra um p-valor de 0,012 para a hipótese H0, um p-valor de 0,000 para a hipótese H1, e um p-valor de 0,119 para a hipótese H2. O teste do Qui Quadrado indica que as hipóteses H0 e H1 devem ser rejeitadas, pois a proporção de respostas entre os gestores quanto gênero e faixa etária e instituição apresentam diferença significativa. Já a hipótese H2 sugere que não deve ser rejeitada por apresentam proporção de respostas semelhantes quando considera o tempo de atuação da empresa no mercado.

No que diz respeito a utilização do plano de negócios como ferramenta de gestão verificou-se que os gestores entrevistados, 74\% não o utiliza, o que pode ser um problema futuro por falta de um planejamento das atividades a serem desenvolvidas pela organização. Porém, vale ressaltar que as empresas geridas por mulheres (25\%) utilizam mais essa ferramenta do que as que são geridas por homens (21,7\%). Outro fator a ser destacado é que os gestores acima de 40 anos são os que menos utilizam do plano de negócios em suas corporações, como 15,4\% apenas. 


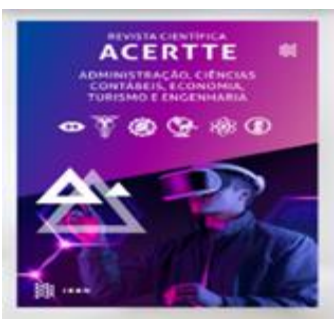

\section{REVISTA CIENTÍFICA ACERTTE ISSN 2763-8928}

Conforme os dados obtidos, de acordo com Cruz e Silva (2015) o plano de negócio é uma ferramenta que auxilia o empreendedor de forma segura, pois com planejamento realizado, seja de cunho mercadológico e financeiro é possível identificar falhas que, se cometidas no mercado, poderia gerar problemas indesejáveis. Um bom planejamento antes da prática pode determinar o sucesso ou insucesso do negócio.

Tabela 7 - Utilização do plano de negócios na empresa

\begin{tabular}{cccccccccc}
\hline & \multicolumn{2}{c}{ Gênero } & \multicolumn{3}{c}{ Faixa etária } & \multicolumn{4}{c}{ Tempo empresa mercado } \\
\hline & Feminino & Masculino & $\mathbf{2 0 / 3 0}$ & $\mathbf{3 1 / 4 0}$ & $\mathbf{4 0}+$ & Até 3 & De 4 / 6 & $\mathbf{6 +}$ & Total \\
\hline Utiliza & $38,6 \%$ & $16,7 \%$ & $55,2 \%$ & $22,2 \%$ & $7,7 \%$ & $28,1 \%$ & $12,9 \%$ & $34,1 \%$ & $26,0 \%$ \\
\hline Não utiliza & $61,4 \%$ & $83,3 \%$ & $44,8 \%$ & $77,8 \%$ & $92,3 \%$ & $71,9 \%$ & $87,1 \%$ & $65,9 \%$ & $74,0 \%$ \\
\hline Total Geral & $100,0 \%$ & $100,0 \%$ & $100,0 \%$ & $100,0 \%$ & $100,0 \%$ & $100,0 \%$ & $100,0 \%$ & $100,0 \%$ & $100,0 \%$ \\
\hline \multicolumn{8}{c}{ Fonte: Dados da pesquisa (2020) }
\end{tabular}

A Tabela 8 objetiva responder à variável "Utilização da análise SWOT na empresa”; mostra um p-valor de 0,335 para a hipótese $\mathrm{H} 0$, um p-valor de 0,241 para a hipótese $\mathrm{H} 1$, e um p-valor de 0,006 para a hipótese $\mathrm{H} 2$. Baseado no teste estatístico, que as hipóteses $\mathrm{H} 0$ e $\mathrm{H} 1$ não devem ser rejeitadas, o que significa que tantos gestores quanto ao gênero e faixa etária não apresenta diferença significativa na proporção das respostas. Por outro lado, os gestores que respondem de acordo com tempo de atuação da empresa no mercado, o teste Qui Quadrado aponta diferença significa, o que deve ser rejeitada a hipótese $\mathrm{H} 2$.

Ao analisar os achados, é possível avaliar que a matriz SWOT é pouco utilizada pelas empresas entrevistadas, onde apenas $26,9 \%$ delas a utilizam como uma ferramenta de gestão, sendo que a maior utilização está entre as empresas com mais de seis anos no mercado (43,9\%) e a de menor utilização é entre as empresas de 4 a 6 anos de existência no mercado.

Diante dos dados obtidos, de acordo com a perspectiva de Martins (2016), a análise SWOT é uma das práticas mais comuns nas empresas voltadas para o pensamento estratégico e marketing, entretanto, é algo relativamente trabalhoso de produzir, contudo a prática constante pode trazer ao profissional uma melhor visão de negócios, afinal de contas, os cenários onde a empresa atua estão sempre mudando.

Tabela 8 - Utilização da análise SWOT na empresa

\begin{tabular}{cccccccccc}
\hline & \multicolumn{3}{c}{ Gênero } & \multicolumn{3}{c}{ Faixa etária } & \multicolumn{3}{c}{ Tempo empresa mercado } \\
\hline & Feminino & Masculino & $\mathbf{2 0} / \mathbf{3 0}$ & $\mathbf{3 1 / 4 0}$ & $\mathbf{4 0}+$ & Até 3 & De 4/ $\mathbf{6}$ & $\mathbf{6}+$ & Total \\
\hline Utiliza & $31,8 \%$ & $23,3 \%$ & $37,9 \%$ & $19,4 \%$ & $25,6 \%$ & $18,8 \%$ & $12,9 \%$ & $\mathbf{4 3 , 9 \%}$ & $26,9 \%$ \\
\hline Não utiliza & $68,2 \%$ & $76,7 \%$ & $62,1 \%$ & $80,6 \%$ & $74,4 \%$ & $81,3 \%$ & $87,1 \%$ & $56,1 \%$ & $73,1 \%$ \\
\hline Total Geral & $100,0 \%$ & $100,0 \%$ & $100,0 \%$ & $100,0 \%$ & $100,0 \%$ & $100,0 \%$ & $100,0 \%$ & $100,0 \%$ & $100,0 \%$ \\
\hline \multicolumn{8}{c}{ Fonte: Dados da pesquisa $(2020)$}
\end{tabular}

A Tabela 9 que tem o questionário a respeito da variável "Utilização do 5W2H na empresa"; apresenta pela aplicação do teste Qui Quadrado um p-valor de 0,727 para a hipótese H0, um p-valor de 0,257 para a hipótese H1, e um p-valor de 0,132 para a hipótese H2. Dessa forma, não apresenta diferenças significativas na proporção de respostas entre os gestores quanto ao gênero, faixa etária e 


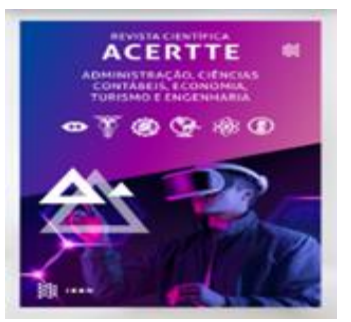

\section{REVISTA CIENTÍFICA ACERTTE ISSN 2763-8928}

tempo de atuação da empresa no mercado, portanto, as hipóteses $\mathrm{H} 0, \mathrm{H} 1$ e H2, não devem ser rejeitadas.

Em relação ao uso da ferramenta $5 \mathrm{~W} 2 \mathrm{H}$, verificou-se que boa parte das empresas $(77,9 \%)$ não utilizam essas estratégias de gestão, onde a maior porcentagem de utilização fica por conta das empresas com mais de seis anos no mercado (31,7\%) e a menos pelas empresas mais novas (12,5\%).

Os achados obtidos indicam que empresas com mais tempo de mercado já tem essa cultura no uso dessa ferramenta. Dessa forma, de acordo com o SEBRAE (2008), a ferramenta 5W2H é uma técnica prática que permite, a qualquer momento, identificar dados e rotinas que são mais importantes em um projeto ou de uma unidade produtiva e também possibilita a identificação de quem é quem dentro da empresa, o que faz e porque realiza tais tarefas, por meio de um plano de ação, uma vez aplicada a análise SWOT.

Tabela 9 - Utilização do 5W2H na empresa

\begin{tabular}{cccccccccc}
\hline & \multicolumn{2}{c}{ Gênero } & \multicolumn{3}{c}{ Faixa etária } & \multicolumn{4}{c}{ Tempo empresa mercado } \\
\hline & Feminino & Masculino & $\mathbf{2 0 / 3 0}$ & $\mathbf{3 1 / 4 0}$ & $\mathbf{4 0 +}$ & Até 3 & De $\mathbf{~ / ~}$ & $\mathbf{6}+$ & Total \\
\hline Utiliza & $20,5 \%$ & $23,3 \%$ & $17,2 \%$ & $16,7 \%$ & $30,8 \%$ & $12,5 \%$ & $19,4 \%$ & $31,7 \%$ & $22,1 \%$ \\
\hline Não utiliza & $79,5 \%$ & $76,7 \%$ & $82,8 \%$ & $83,3 \%$ & $69,2 \%$ & $87,5 \%$ & $80,6 \%$ & $68,3 \%$ & $77,9 \%$ \\
\hline Total Geral & $100,0 \%$ & $100,0 \%$ & $100,0 \%$ & $100,0 \%$ & $100,0 \%$ & $100,0 \%$ & $100,0 \%$ & $100,0 \%$ & $100,0 \%$ \\
\hline \multicolumn{4}{c}{ Fonte: Dados da pesquisa $(2020)$} \\
\hline
\end{tabular}

A Tabela 10 refere-se à variável "Utilização do CRM na empresa"; apresenta um p-valor de 0,881 para a hipótese $\mathrm{H} 0$, um p-valor de 0,981 para a hipótese $\mathrm{H} 1$, e um p-valor de 0,211 para a hipótese $\mathrm{H} 2$, indicando que as hipóteses $\mathrm{H} 0, \mathrm{H} 1$ e $\mathrm{H} 2$ não devem ser rejeitadas, ou seja, nos cruzamentos dos dados por gênero, faixa etária e instituição, não há diferença significativa entre as respostas.

No que diz respeito ao uso do sistema de CRM, é possível notar que este não é utilizado pela maioria das empresas pesquisadas (78,8\%). Vale ressaltar que a maior porcentagem de uso é entre as empresas que estão a mais de seis anos inseridas no mercado (29,3\%), porém sendo este um valor baixo levando em conta os benefícios que esse sistema de gestão traz às organizações. Nesse contexto, Nascimento, Saito e Alves (2016) apontam que a ferramenta do CRM é uma estratégia tecnológica viável e rentável para o gerenciamento do relacionamento com o cliente desde que a organização tenha comprometimento, suporte e controle com indicadores para monitorar o feedback do cliente bem como gerar soluções para as insatisfações.

Seguindo o mesmo pensamento, Liggyeri (2014) ressalta que o CRM se trata de uma estratégia de gestão de negócios por meio do relacionamento com o cliente, para a efetivação de aumentar a lucratividade e vantagens competitivas perante aos concorrentes, sendo que a tecnologia é responsável por automatizar os vários processos das negociações, tais como venda, marketing, consumidor, serviços ou produtos ao consumidor. 


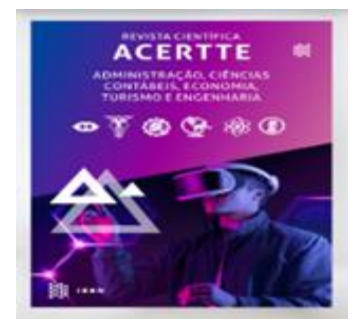

\section{REVISTA CIENTÍFICA ACERTTE} ISSN 2763-8928

FERRAMENTAS DA ADMINISTRAÇÃO: COMO SÃO APLICADAS NA GESTÃO EMPRESARIAL NA FIDELIZAÇÃO DE CLIENTES? Claudio Chiusoli, Elizabeth Emperatriz Garcia-Salirrosas, Thiago Ferreira Spiri, Andressa Antonio

\begin{tabular}{|c|c|c|c|c|c|c|c|c|c|}
\hline & \multicolumn{2}{|c|}{ Gênero } & \multicolumn{3}{|c|}{ Faixa etária } & \multicolumn{4}{|c|}{ Tempo empresa mercado } \\
\hline & Feminino & Masculino & $20 / 30$ & $31 / 40$ & $40+$ & Até 3 & $\operatorname{De~} 4 / 6$ & $6+$ & Total \\
\hline Utiliza & $20,5 \%$ & $21,7 \%$ & $20,7 \%$ & $22,2 \%$ & $20,5 \%$ & $12,5 \%$ & $19,4 \%$ & $29,3 \%$ & $21,2 \%$ \\
\hline Não utiliza & $79,5 \%$ & $78,3 \%$ & $79,3 \%$ & $77,8 \%$ & $79,5 \%$ & $87,5 \%$ & $80,6 \%$ & $70,7 \%$ & $78,8 \%$ \\
\hline Total Geral & $100,0 \%$ & $100,0 \%$ & $100,0 \%$ & $100,0 \%$ & $100,0 \%$ & $100,0 \%$ & $100,0 \%$ & $100,0 \%$ & $100,0 \%$ \\
\hline
\end{tabular}

A Tabela 11 refere-se à variável "Forma de contato com os clientes"; aponta um p-valor de 0,917 para a hipótese $\mathrm{H} 0$, um p-valor de 0,178 para a hipótese $\mathrm{H} 1$, e um p-valor de 0,521 para a hipótese H2. Dessa forma, indica por meio do teste Qui Quadrado que as hipóteses H0, H1 e H2 não devem ser rejeitadas, uma vez que os dados obtidos na proporção de respostas dos gestores em relação ao gênero, faixa etária e tempo de atuação da empresa no mercado, não apresentam diferenças significativas.

Quando perguntado como as empresas fazem para manter contato com seus clientes, a maioria delas $(58,8 \%)$ respondeu que utiliza das redes sociais e o meio menos utilizado foi o e-mail (1,9\%). Vale ressaltar que uma parcela das organizações entrevistadas $(16,3 \%)$ não mantém contato com seus clientes no pós-venda, principalmente entre as empresas mais novas de mercado (até 3 anos) onde o índice é de $28,1 \%$.

Considerando os achados, quanto mais tempo um cliente continuar a comprar com a empresa, o lucro da organização tende a aumentar, tornando o cliente mais dependente dos produtos ou serviços dessa organização, e dessa forma o cliente estará menos propenso a conhecer ofertas da concorrência (MILAN; RIBEIRO, 2014).

\section{Tabela 11 - Forma de contato com os clientes}

\begin{tabular}{|c|c|c|c|c|c|c|c|c|c|}
\hline & \multicolumn{2}{|c|}{ Gênero } & \multicolumn{3}{|c|}{ Faixa etária } & \multicolumn{3}{|c|}{ Tempo empresa mercado } & \multirow[b]{2}{*}{ Total } \\
\hline & Feminino & Masculino & $20 / 30$ & $31 / 40$ & $40+$ & Até 3 & De 4 / 6 & $6+$ & \\
\hline Redes sociais & $56,8 \%$ & $60,0 \%$ & $44,8 \%$ & $66,7 \%$ & $61,5 \%$ & $53,1 \%$ & $67,7 \%$ & $56,1 \%$ & $58,7 \%$ \\
\hline Não faço & $18,2 \%$ & $15,0 \%$ & $24,1 \%$ & $5,6 \%$ & $20,5 \%$ & & & $12,2 \%$ & $16,3 \%$ \\
\hline Telefone & $15,9 \%$ & & $20,7 \%$ & $19,4 \%$ & $5,1 \%$ & & $12,9 \%$ & $17,1 \%$ & $14,4 \%$ \\
\hline Indo aos clientes & & & $10,3 \%$ & & $7,7 \%$ & & & & $8,7 \%$ \\
\hline E-mail & $0,0 \%$ & $3,3 \%$ & $0,0 \%$ & $0,0 \%$ & $5,1 \%$ & $0,0 \%$ & $0,0 \%$ & $4,9 \%$ & $1,9 \%$ \\
\hline Total Geral & $100,0 \%$ & $100,0 \%$ & $100,0 \%$ & $100,0 \%$ & $100,0 \%$ & $100,0 \%$ & $100,0 \%$ & $100,0 \%$ & $100,0 \%$ \\
\hline
\end{tabular}

$$
\text { Fonte: Dados da pesquisa (2020) }
$$

A Tabela 12 apresenta os resultados da variável "Forma de avaliar a satisfação dos clientes"; que tem um p-valor de 0,178 para a hipótese $\mathrm{H} 0$, um p-valor de 0,155 para a hipótese H1, e um p-valor de 0,197 para a hipótese H2. O teste aplicado incida que as hipóteses $\mathrm{H} 0, \mathrm{H} 1$ e H2 não devem ser rejeitadas, uma vez que na segmentação quanto ao perfil do gestor por gênero, faixa etária e tempo de atuação da empresa no mercado, não apresenta diferença significativa entre as respostas quanto a sua proporção.

Os resultados mostram os meios mais empregados pelas empresas entrevistadas para avaliar o nível de satisfação dos clientes. Verifica-se que é possível analisar que muitas das organizações pesquisadas $(34,6 \%)$ não utilizam nenhuma ferramenta para levantar o quanto seus clientes estão 


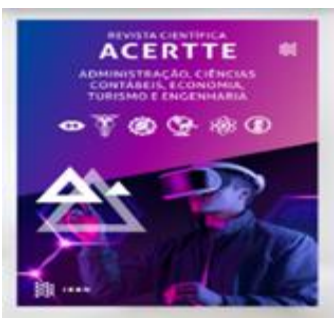

\section{REVISTA CIENTÍFICA ACERTTE ISSN 2763-8928}

satisfeitos com seus produtos e/ou serviços. Dentre os meios mais utilizados, foram as avaliações em mídias sociais $(26,9 \%)$ e a menos utilizada são as pesquisas com cliente $(6,7 \%)$.

Essa atitude de pouco pesquisar clientes diretamente, provavelmente se deve ao fato de que as pesquisas geram custos e levam tempo, já as avaliações em redes sociais são gratuitas e imediatas, porém muitas vezes não revelam muitos fatores que as pesquisas podem apontar.

Para Oliveira (2015), aumentar a satisfação de um cliente pode ser entendida pela qualidade percebida por ele, pois esse indicador equivale ao intervalo entre o serviço esperado e a percepção do serviço realmente recebido.

Não se pode inferiorizar a importância da satisfação do cliente, pois sem clientes a empresa não tem razão de existir, as empresas precisam identificar o grau de satisfação. Esperar que os clientes reclamem para identificar os problemas dentro da organização, no que diz respeito a satisfação do cliente, é uma atitude nada adequada (GIULIANI,2016).

Tabela 12 - Forma de avaliar a satisfação dos clientes Gênero Faixa etária Tempo empresa mercado

\begin{tabular}{cccccccccc}
\hline & \multicolumn{2}{c}{ Gênero } & \multicolumn{3}{c}{ Faixa etária } & \multicolumn{5}{c}{ Tempo empresa mercado } \\
\hline & Feminino & Masculino & $\mathbf{2 0 ~ / 3 0}$ & $\mathbf{3 1 / 4 0}$ & $\mathbf{4 0}+$ & Até 3 & De 4 / 6 & $\mathbf{6}+$ & Total \\
\hline Nenhuma & $29,5 \%$ & $38,3 \%$ & $48,3 \%$ & $27,8 \%$ & $30,8 \%$ & $53,1 \%$ & $19,4 \%$ & $31,7 \%$ & $34,6 \%$ \\
\hline Nas mídias sociais & $27,3 \%$ & $26,7 \%$ & $13,8 \%$ & $36,1 \%$ & $28,2 \%$ & $18,8 \%$ & $41,9 \%$ & $22,0 \%$ & $26,9 \%$ \\
\hline Perguntando clientes & $25,0 \%$ & $15,0 \%$ & $31,0 \%$ & $11,1 \%$ & $17,9 \%$ & $15,6 \%$ & $19,4 \%$ & $22,0 \%$ & $19,2 \%$ \\
\hline Ferramentas CRM & $6,8 \%$ & $16,7 \%$ & $3,4 \%$ & $16,7 \%$ & $15,4 \%$ & $9,4 \%$ & $12,9 \%$ & $14,6 \%$ & $12,5 \%$ \\
\hline Pesquisas cliente & $11,4 \%$ & $3,3 \%$ & $3,4 \%$ & $8,3 \%$ & $7,7 \%$ & $3,1 \%$ & $6,5 \%$ & $9,8 \%$ & $6,7 \%$ \\
\hline Total Geral & $100,0 \%$ & $100,0 \%$ & $100,0 \%$ & $100,0 \%$ & $100,0 \%$ & $100,0 \%$ & $100,0 \%$ & $100,0 \%$ & $100,0 \%$ \\
\hline
\end{tabular}
Fonte: Dados da pesquisa (2020)

Em resumo, destaca-se por meio da Tabela 13 os resultados quanto ao teste Qui Quadrado, considerando as hipóteses $\mathrm{H} 0, \mathrm{H} 1$ e H2, devendo ser rejeitadas ou não ao nível de significância de $1 \%$ $(p \leq 0,01)$ e $5 \%(p \leq 0,05)$.

Considerando o teste Qui Quadrado na leitura dos resultados, quando comparado por gênero, faixa etária e tempo de empresa no mercado, verificou-se que as respostas são muitos semelhantes, não apresentando diferenças estatísticas.

Cabe destaque para a variável "Perfil do gestor quanto a faixa etária" onde os respondentes quanto ao gênero feminino são mais jovens. Na variável "Utilização do plano de negócios na empresa" os gestores do gênero masculino e de maior faixa etária são os que mais fazem uso dessa ferramenta.

E por último, a variável "Utilização da análise SWOT na empresa", são as empresas com mais tempo de mercado que fazem uso dessa ferramenta. 


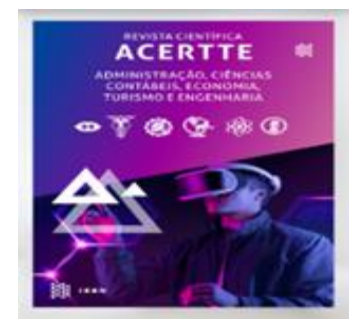

\section{REVISTA CIENTÍFICA ACERTTE ISSN 2763-8928}

Tabela 13 - Resumo do teste estatístico não paramétrico: Qui Quadrado

NA FIDELIZAÇÃO DE CLIENTES?
Claudio Chiusoli, Elizabeth Emperatriz Garcia-Salirrosas, Thiago Ferreira Spiri, Andressa Antonio

\begin{tabular}{|c|c|c|c|c|c|c|}
\hline & & Teste hipótese & & Teste hipótese & & Teste hipótese \\
\hline & P-valor & Gênero & P-valor & Faixa etária & P-valor & Tempo empresa \\
\hline Tabela 1 & & - & & & & Não rejeitar H2 \\
\hline Tabela 2 & $0,039^{* *}$ & Rejeitar H0 & 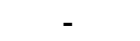 & & 0,083 & Não rejeitar H2 \\
\hline Tabela 3 & 0,515 & Não rejeitar H0 & 0,083 & Não rejeitar H1 & & \\
\hline Tabela 4 & 0,296 & Não rejeitar HO & 0,141 & Não rejeitar H1 & 0,226 & Não rejeitar H2 \\
\hline Tabela 5 & 0,752 & Não rejeitar HO & 0,382 & Não rejeitar H1 & 0,270 & Não rejeitar H2 \\
\hline Tabela 6 & 0,690 & Não rejeitar HO & 0,353 & Não rejeitar H1 & 0,389 & Não rejeitar H2 \\
\hline Tabela 7 & $0,012^{\star \star}$ & Rejeitar H0 & $0,000^{*}$ & Rejeitar H1 & 0,119 & Não rejeitar H2 \\
\hline Tabela 8 & 0,335 & Não rejeitar HO & 0,241 & Não rejeitar H1 & $0,006^{*}$ & Rejeitar H2 \\
\hline Tabela 9 & 0,727 & Não rejeitar HO & 0,257 & Não rejeitar H1 & 0,132 & Não rejeitar H2 \\
\hline Tabela 10 & 0,881 & Não rejeitar HO & 0,981 & Não rejeitar H1 & 0,211 & Não rejeitar H2 \\
\hline Tabela 11 & 0,917 & Não rejeitar HO & 0,178 & Não rejeitar H1 & 0,521 & Não rejeitar H2 \\
\hline Tabela 12 & 0,178 & Não rejeitar HO & 0,155 & Não rejeitar H1 & 0,197 & Não rejeitar H2 \\
\hline
\end{tabular}

\section{CONSIDERAÇÕES FINAIS}

O relato de pesquisa buscou analisar como se dá o uso das ferramentas da administração na prática da gestão empresarial com o respectivo processo de satisfação e fidelização com o cliente.

Além disso, contribuiu ao analisar como as empresas fazem para satisfazer e fidelizar seus clientes, se utilizam alguma ferramenta de gestão para isso e quais estratégias são utilizadas em busca de um relacionamento duradouro, bem como avaliam o nível de satisfação dos clientes com os produtos e/ou serviços. Ao analisar os resultados da pesquisa aplicada em empresas de diferentes ramos no município, foi possível identificar que a maioria delas não utiliza os recursos do sistema de CRM, bem como de outras ferramentas de gestão.

Isso se deve ao fato de essas organizações serem de pequeno porte e, portanto, consideram inviável o uso de sistemas de gestão por meio de novos sistemas tecnológicos ou as vezes nem tem acesso ao mesmo.

Vale ressaltar que o maior percentual de uso do sistema de CRM e das outras ferramentas são pelas empresas que estão inseridas no mercado a mais tempo, pois já estão consolidadas e tem maior segurança em investir nesses sistemas.

No que diz respeito ao processo de satisfação e consequentemente de fidelização dos clientes, verificou-se que a maior parte das empresas pesquisadas utilizam estratégias de promoção para atrair e manter seus clientes, tais como investimentos em propaganda, cartão fidelidade, entre outras. Quando perguntado quais os principais meios para manter contato com os clientes e para avaliar o nível de satisfação dos mesmos, constatou-se que as redes sociais foram os recursos mais utilizados pelas empresas. Isso porque o uso da maior parte das mídias sociais é gratuito e o resultado é imediato, diferentemente de uma pesquisa mais elaborada.

Entretanto, muitos fatores não são levados em consideração nas avaliações em redes sociais, fazendo com que os resultados sejam restritos a poucos aspectos.

Considerando os objetivos propostos, apresenta-se os principais achados e os resultados do teste de hipótese: 


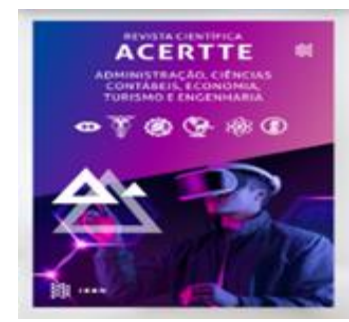

\section{REVISTA CIENTÍFICA ACERTTE ISSN 2763-8928}

- $32,3 \%$ utilizam a propaganda e promoções como estratégias para atrair novos clientes, logo, as hipóteses $\mathrm{H} 0, \mathrm{H} 1$ e $\mathrm{H} 2$ não devem ser rejeitadas;

- $58,7 \%$ utilizam as redes sociais como forma de contato com o cliente, logo, as hipóteses H0, H1 e H2 não devem ser rejeitadas;

- $65,4 \%$ utilizam alguma ferramenta como forma de avaliar a satisfação dos clientes, logo, as hipóteses $\mathrm{H} 0, \mathrm{H} 1$ e $\mathrm{H} 2$ não devem ser rejeitadas;

- $29,6 \%$ utilizam o cartão fidelidade como estratégia de fidelização do cliente, logo, as hipóteses $\mathrm{H} 0, \mathrm{H} 1$ e $\mathrm{H} 2$ não devem ser rejeitadas;

- $23,1 \%$ utilizam o ciclo PDCA como estratégia da empresa, logo, as hipóteses H0 e H1 devem ser rejeitadas enquanto a hipótese $\mathrm{H} 2$ não deve ser rejeitada;

- $26,0 \%$ utilizam do plano de negócios como estratégia da empresa, logo, as hipóteses H0

e H1 devem ser rejeitadas, enquanto, a hipótese H2 não deve ser rejeitada;

- 26,9\% utilizam a análise SWOT como estratégia da empresa, logo, as hipóteses H0 e H1 não devem ser rejeitadas, enquanto, a hipótese $\mathrm{H} 2$ deve ser rejeitada;

- $22,1 \%$ utilizam o 5W2H como estratégia da empresa, logo, as hipóteses H0, H1 e H2 não devem ser rejeitadas;

- 21,2\% utilizam o CRM como estratégia da empresa, logo, as hipóteses H0, H1 e H2 não devem ser rejeitadas;

Portanto, como contribuição do relato de pesquisa, considera-se que o uso das ferramentas do sistema de CRM e de outros pesquisados traz benefícios para as organizações em busca de uma vantagem competitiva. Então, O CRM (Customer Relashionship Management) pode se tornar uma estratégia de negócio com foco em aperfeiçoar a lucratividade, aumentar as vendas e manter a satisfação dos clientes, podendo também ser aplicado em micro e pequenas empresas.

Essas organizações, atualmente, podem deter dessa e de outras ferramentas tecnológicas, sendo possível a aplicação dos recursos do CRM como a implantação de gerenciadores de banco de dados, sistemas gratuitos ou pagos de CRM ou mesmo planilhas eletrônicas mais simples.

Como limitação do estudo, por trata-se de amostragem não probabilísticas, a análise deve ficar restrita ao grupo de gestores investigados e da mesma forma, são perfis de empresas de pequeno porte e familiar. Certamente, estudos semelhantes, com condições e outros perfis podem apresentar resultados distintos.

Como estudos futuros, pode ser ampliado o escopo da investigação avaliando com mais detalhes como as empresas estão empregando as ferramentas de gestão, bem como aumentar a abrangência do perfil da empresa para médio ou grande porte.

\section{REFERÊNCIAS}

ALMEIDA, S. Cliente eu não vivo sem você. 9. ed. Salvador: Casa da Qualidade, 2017. 


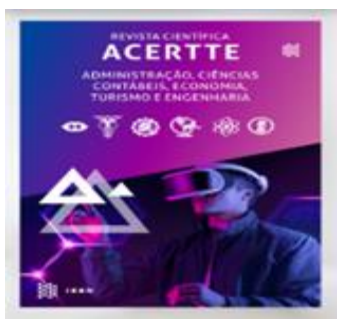

\section{REVISTA CIENTÍFICA ACERTTE ISSN 2763-8928}

ALVES, É. A. C. O PDCA como ferramenta de gestão da rotina. In.: XI congresso nacional de excelência em gestão. São Paulo, 2015.

ARAUJO, K. V. Marketing de relacionamento como ferramenta para atrair, manter e fidelizar o cliente. 2016. Disponível em: file:///C:/Users/robin/Downloads/7-44-1-PB.pdf. Acesso em: 12 nov. 2020.

CRUZ, B. C.; SILVA, R. V. O. Plano de negócios e planejamento: sua importância para o empreendimento. In.: V encontro científico e simpósio de educação Unisalesiano. São Paulo, 2015. DIAS, S. R. et al. Gestão de marketing. São Paulo: Saraiva, 2015.

EVERATT, D.; ALLEN, M. CRM Easy to do wrong, hard to do right. Strategic direction. Emerald Group Publishing Limited, 2015.

FERREIRA, J. D.; FILIPCHIUK, B.; SILVA, T. G. O marketing para a fidelização de clientes: análise de caso buffet Donebelli. São Paulo: ENGEMA, 2014. Disponível em: http://engemausp.submissao.com.br/17/anais/arquivos/32.pdf. Acesso em: 03 ago. 2020.

FONSECA, J. J. S. Metodologia da pesquisa científica. Fortaleza: UEC, 2017.

GIL, A. C. Como elaborar projetos de pesquisa. 6. ed. São Paulo: Atlas, 2017.

GIULIANI, A. C. Marketing contemporâneo: novas práticas de gestão com estudo de casos brasileiros. São Paulo: Saraiva, 2016.

KOTLER, P. Marketing de A a Z: 80 conceitos que todo profissional precisa saber. Rio de Janeiro. Campus, 2003.

LIGGYERI, S. Conheça mais sobre CRM - Customer Relationship Management. São Paulo: Bookman, 2014. Disponível em: http://www.guiarh.com.br/y77.html. Acesso em: 5 nov. 2020.

MADRUGA, R. Guia de Implementação de Marketing de Relacionamento e CRM. São Paulo: Atlas, 2004.

MARTINS, L. Marketing: como se tornar um profissional de sucesso. 3. ed. São Paulo: Digerati Books, 2016.

MEDEIROS, S. T. CRM - estratégia para aproveitamento de conhecimento. Developers' Magazine, ano $\mathrm{VI}$, nov. 2016.

MILAN, G. S.; RIBEIRO, J. L. D. A influência do departamento de pós-vendas na retenção de clientes: um estudo qualitativo em uma empresa de medicina de grupo. Gest. Prod. [online]. 2014.

NASCIMENTO, B. G. M. F.; SAITO, E. S.; ALVES, L. A. S. O CRM contribuindo na gestão do relacionamento com o cliente: um estudo de caso nas Lojas Tanger LTDA. Monografia (Trabalho de Conclusão de Curso) - Centro Católico Salesiano Auxilium, São Paulo, 2016.

NEPOMUCENA, F. V. Marketing de relacionamento para retenção de clientes. 2014 Disponível em: http://www.unipacto.com.br/revista2/arquivos pdf revista/revista2016/MARKETINGDERELACIONAM ENTO.pdf. Acesso em: 08 nov. 2020.

OLIVEIRA, O. J. Gestão da qualidade: tópicos avançados. São Paulo: Thompson, 2016.

OLIVEIRA, W. J. CRM \& e-business. Florianópolis: Visual Books, 2015.

PEPPERS, D.; ROGERS, M. One to one manager: real-world lessons in customer relationship management. New York: Currency/Doubleday, 2014.

ACERTTE - Administração, Ciências Contábeis, Economia, Turismo, Tecnologia e Engenharia 


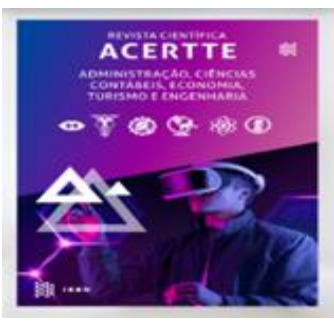

\section{REVISTA CIENTÍFICA ACERTTE ISSN 2763-8928}

POLIT, D. F.; BECK, C. T.; HUNGLER, B. P. Fundamentos de pesquisa em enfermagem: métodos, avaliação e utilização. 5. ed. Porto Alegre: Artmed, 2014.

RÁIZ, B. L.; MARTARELLO, E. E. D.; LIMA, F. E. G. Estratégia de marketing para captação de clientes - Unimed Lins. Revista Científica do Unisalesiano, Lins, 2015. Disponível em: http://www.salesianolins.br/universitaria/artigos/no7/artigo35.pdf. Acesso em: 27 out. 2020.

SALES, K. N. Programa de fidelização do cliente de pós-vendas no ramo automobilístico. Sociedade de educação e cultura de Goiânia, Faculdade padrão Goiânia, Goiás, 2014. Disponível em: http://www.faculdadepadrao.com.br/portal/index.php/tcc/doc download/213programa-de-fidelizacaodo-cliente-de-pos-vendas-no-ramo-automobilistico. Acesso em: 25 jun. 2020.

SEBRAE. Ferramenta 5W2H. São Paulo: Sebrae, 2008. Disponível em: http://www.trema.gov.br/qualidade/cursos/5w 2h.pdf. Acesso em: 26 de out. de 2020.

SCHIFFMAN, L., KANUK, L. Comportamento do consumidor. 6. ed. São Paulo: LTC, 2015.

SILVA, A. da. Marketing de relacionamento: uma ferramenta para o sucesso. 2014. Disponível em: http://www.uniedu.sed.sc.gov.br/wpcontent/uploads/2014/04/Andreda-Silva.pdf. Acesso em: 14 out. 2020.

SILVA, Edson Coutinho; MINCIOTTI, Silvio Augusto; GIL, Antonio Carlos. Resgatando o conceito de Marketing Social. Administração Pública e Gestão Social, p. 63-70, 2013.

SOUSA, F. J. Satisfação de Clientes: o caso de uma empresa industrial. Dissertação (Mestrado em Marketing) - Faculdade de Economia da Universidade de Coimbra: Coimbra, 2016. Disponível em: https://estudogeral.sib.uc.pt/bitstream/10316/16192/2/Satisfa\%C3\%A7\%C3\%A30\%20de\%20Clientes O\%20Caso\%20de\%20Uma\%20Empresa\%20Industrial.pdf. Acesso em: 31 out 2020.

SIEGEL, Sidney; CASTELLAN, Jr, N. John Estatística Não Paramétrica para as Ciências do Comportamento. Artmed-Bookman. São Paulo, 2017.

SWIFT, R. CRM: O revolucionário marketing de relacionamento. Rio de Janeiro: Campus, 2014.

TORRES, S. P.; FONSECA, S. C. Marketing de relacionamento: a satisfação e fidelização do cliente. Instituto de Ensino Superior Presidente Tancredo de Almeida Neves. Minas Gerais, 2016. Disponível em: https://www.prolucroconsultoria.com.br/download/Artigo Simone Sonia.pdf. Acesso em: 03 ago. 2020

TRIVIÑOS, A. N. S. Introdução à pesquisa em ciências sociais: a pesquisa qualitativa em educação. São Paulo: Atlas, 2015

ZEITHAML, V. A.; BITNER, M. J. Marketing de serviços: a empresa com foco no cliente. São Paulo: Bookman, 2017. 